Revista do Departamento de Geografia
Universidade de São Paulo
www.revistas.usp.br/rdg

\title{
Influência do Uso e Cobertura da Terra Aliado à Precipitação Pluviométrica na Qualidade da Água da Bacia Hidrográfica do Rio Ingaí - RS/Brasil
}

\author{
Influence of Use and Land Cover Combined with Rainfall on \\ Water Quality of the Watershed of Ingai River-RS/Brazil
}

\author{
Makele Rosa de Paula \\ Universidade Federal de Santa Maria \\ makeleufsm@hotmail.com \\ Ana Caroline Paim Benedetti \\ Universidade Federal de Santa Maria \\ anacaroline@politecnico.ufsm.br \\ Waterloo Pereira Filho \\ Universidade Federal de Santa Maria \\ waterloopf@gmail.com
}

Recebido (Received): 18/08/2016 DOI: $10.11606 /$ rdg.v2i0.119330
Aceito (Accepted): 15/12/2016

\begin{abstract}
The impacts resulting from human action generates a series of changes in water quality. In this sense, the objective of this research is to analyze the influence use and land cover and of rainfall of the watershed of Ingai river the water quality parameters the same. From Landsat 5/TM images they were performed use and land cover of maps for the dates 21/01/2009 (vegetative period - agriculture) and 20/10/2009 (period between harvests - soil exposed). For this, we used the system software SPRING 4.3.3. The classes use and land cover were defined: forest, agriculture, soil exposed, urban area, water and field. Together the data of precipitation and use and land cover were observed then their influences in some limnological parameters: total of solids in suspension (TSS), water transparency (DS), chlorophyll a (Chl a), water temperature (temp.), hydrogen potential $(\mathrm{pH})$ e electric conductivity $(\mathrm{CE})$. It is concluded that the change of the properties of water from the Ingai river has strong relationship with changes in use and land cover of the watershed, mainly from diffuse sources, due to the extensive area intended for agriculture, soil exposed areas, allies the occurrence of rainfall.
\end{abstract}

Keywords: Water quality; Limnological Variables; Land Use, Ingaí River.

Palavras-Chave: Qualidade da Água; Variáveis Limnológicas, Uso da Terra, Rio Ingaí. 


\section{INTRODUÇÃO}

A intervenção antrópica tem afetado a qualidade dos recursos hídricos em todo o mundo (MISERENDINO et al., 2011), alterando profundamente o ciclo hidrológico, causando impactos econômicos e sociais e, em alguns casos alterações permanentes e irreversíveis em lagos, rios e represas (TUNDISI e TUNDISI, 2008), tornando os custos de tratamento da água mais elevados. Para tal, conhecer a relação entre o uso e cobertura da terra e a qualidade da água é indispensável para identificação de principais ameaças à qualidade da água, no intuito de subsidiar a gestão de recursos hídricos.

O levantamento do uso da terra em uma determinada região tornou-se um aspecto fundamental para a compreensão dos padrões de organização do espaço (ROSA, 2009). Uma vez que os ecossistemas aquáticos continentais estão submetidos a um conjunto de impactos resultantes das atividades humanas e dos usos múltiplos das bacias hidrográficas os quais estão inseridos (TUNDISI e TUNDISI, 2008).

As várias atividades humanas e o acúmulo de usos múltiplos implicam em diferentes ameaças e problemas para a disponibilidade de água, tais como o processo de eutrofização, devido a formação de aglomerados urbanos e da produção agrícola e industrial (TUNDISI e TUNDISI, 2008); a elevada carga de sólidos carreados para corpos d'água, ocasionando assoreamento de rios, lagos e reservatórios (CURRAN e NOVO, 1988; LATRUBESSE et al., 2005; TYLER et al., 2006; LATRUBESSE et al., 2012), além de afetar a qualidade da água e sua adequação quanto ao consumo, recreação, e para fins industriais (LODHI et al., 1997), o que compromete o equilíbrio dos ecossistemas terrestre e aquático. Isso gera grande preocupação, sendo imprescindíveis estudos de ambientes aquáticos, com intuito de monitorar e adotar medidas adequadas quanto a preservação ou recuperação.

Nesse sentido, faz-se necessário o uso do sensoriamento remoto, o qual contribui nos estudos dos ecossistemas terrestre e aquático, dentre os quais destacam-se: estudos realizados no Estado de Ohio por Tong e Chen (2002), a partir da modelagem hidrológica e de qualidade da água mostraram que os usos agrícolas e urbanos, produziram um nível muito mais elevado de nitrogênio e fósforo do que outros usos da terra, o que permitiram verificar a existência de uma relação entre o uso da terra e a qualidade da água de superfície. Reis (2006) relacionou dados de uso da terra com o ecossistema aquático da sub-bacia hidrográfica do Arroio Cadena, identificando os pontos críticos quanto às condições ambientais e concluiu, de maneira geral, que o ecossistema aquático está comprometido, em virtude das formas inadequadas de usos da terra.

A escolha da bacia hidrográfica do rio Ingaí como área de estudo levou em consideração o fato de apresentar intensa atividade agrícola e expressivas alterações da paisagem original. Diante do exposto o objetivo geral consiste em analisar o uso da terra e da chuva em variáveis limnológicas do rio Ingaí considerando sua área de captação e interface com reservatório de Passo Real.

\section{CARACTERIZAÇÃO GERAL DA ÁREA DE ESTUDOS}

O rio Ingaí nasce no município de Cruz Alta e é afluente da margem direita do reservatório Passo Real, sendo um dos principais afluentes afetados pela construção deste reservatório. Sua bacia possui uma área de aproximadamente 1.044,39 km² (de acordo com a delimitação realizada neste estudo), localizada na porção Centro-Norte do Estado do Rio Grande do Sul, no Sul do Brasil (Figura 1). A bacia hidrográfica do Alto Jacuí, da qual a bacia hidrográfica do rio Ingaí faz parte, enquadra-se nos sistemas ambientais naturais fortemente transformados pelas práticas econômicas, apresentando grandes áreas ocupadas por agricultura, silvicultura e pastagens (ROSS, 2006). A vegetação natural local caracteriza-se pela presença de Estepe (Gramíneo-Lenhosa e Floresta Estacional Decidual (Floresta Caducifólia). Atualmente foram substituídas, em sua maioria, por atividades agrárias (IBGE, 2004).

Os solos da bacia foram classificados como Latossolo Vermelho e Nitossolo Háplico (IBGE, 2001). De acordo com a classificação de Köppen o clima é do tipo subtropical úmido (Cfa), com distribuição anual da pluviometria (entre 1.250 e $2.000 \mathrm{~mm}$ ), associadas as baixas temperaturas do inverno (MENDONÇA e DANNIOLIVEIRA, 2007). 


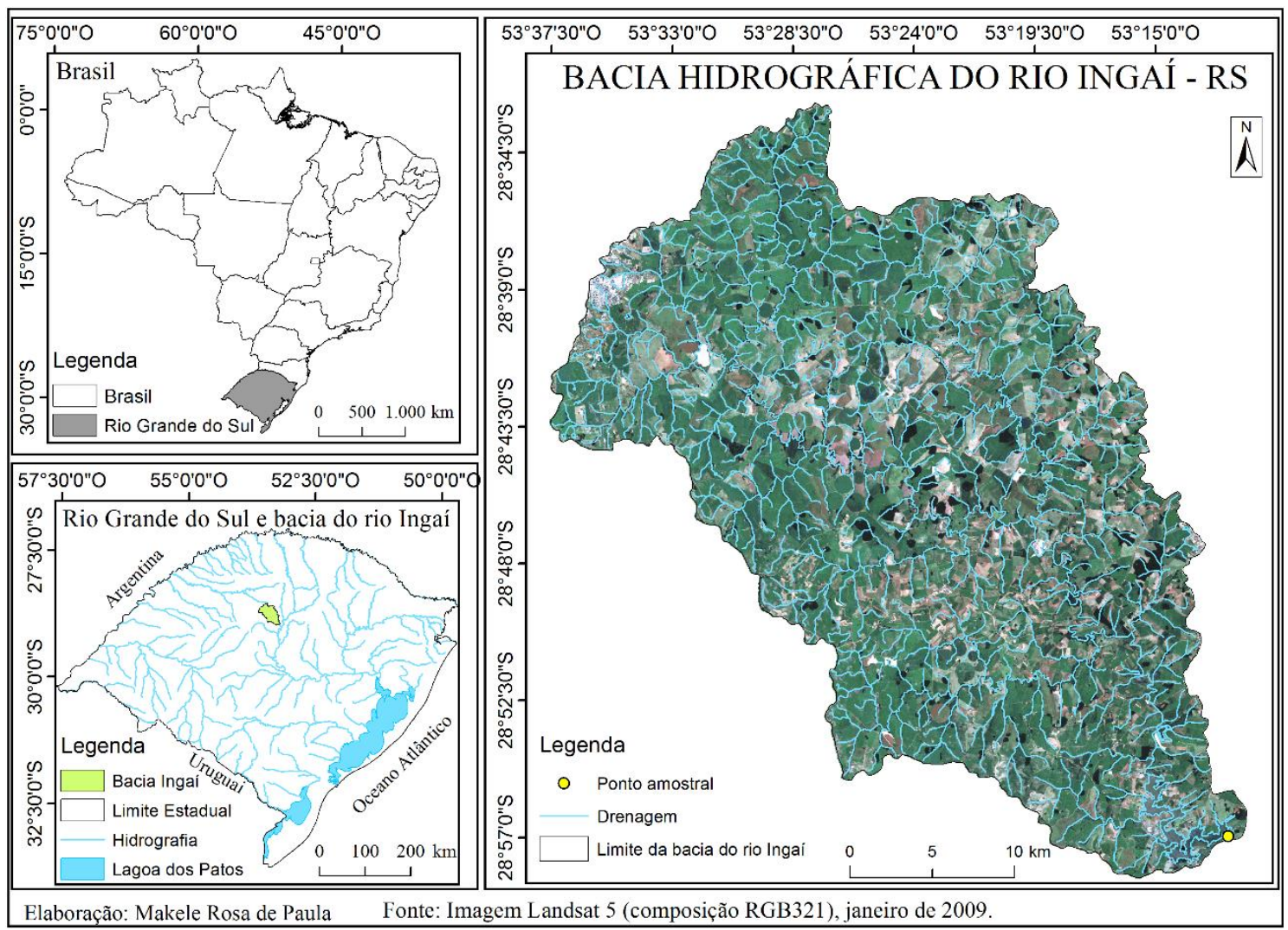

Figura 1: Localização da bacia hidrográfica do rio Ingaí. Fonte: Imagem Landsat 5 e base cartográfica vetorial contínua do Rio Grande do Sul (HASENACK e WEBER, 2010).

\section{MATERIAL E MÉTODO}

Os mapas de uso e cobertura da terra foram obtidos a partir das imagens do sensor Thematic Mapper/Landsat 5 (órbita/ponto: 223/80) para as datas: 21/01/2009 (período vegetativo - agricultura) e 20/10/2009 (período de entressafra - solo exposto), disponibilizadas pela United States Geological Survey (USGS).

As imagens foram georreferenciadas usando como referência a imagem do sensor Operational Land Imager (OLI) a bordo do satélite Landsat 8, de abril de 2015, órbita/ponto 223/80. Após o georreferenciamento das imagens, a bacia hidrográfica foi delimitada utilizando curvas de nível e rede de drenagem, considerando os divisores de água.

A classificação digital das imagens de satélite foi realizada pela adoção do classificador Máxima Verossimilhança (MaxVer), com limiar de aceitação de 100\%. O classificador MaxVer, de acordo com o INPE (2008), considera a ponderação das distâncias entre as médias dos valores dos pixels das classes, utilizando parâmetros estatísticos.

Os mapeamentos foram realizados com base em seis classes temáticas, considerando a área de estudo: floresta (áreas de cobertura vegetal natural e áreas de florestamento); água (compreende a rede de drenagem, braço do reservatório Passo Real e açudes); agricultura (áreas destinadas ao cultivo agrícola); solo exposto (áreas preparadas para o plantio e ausência de vegetação); área urbana (áreas urbanizadas) e campo (áreas com gramíneas). As áreas urbanas foram interpretadas visualmente e delimitadas por edição vetorial, sendo inseridas a partir da edição matricial.

Após a definição das classes temáticas, foram escolhidas as amostras de treinamento representativas de cada uma dessas classes de interesse a fim de treinar o algoritmo de classificação supervisionada. Posteriormente, realizou-se a edição matricial por meio de análise visual, no intuito de corrigir pixels classificados erroneamente pelo classificador. Os layouts dos mapas foram realizados no software ArcGis 10.1 (ESRI Inc., 2013).

Os dados de precipitação pluviométrica foram obtidos no site do Instituto Nacional de Meteorologia (INMET) oriundos da estação climatológica de Cruz Alta - RS (S -28 37'28”/ O -53 36' 42”), referentes aos 
30 dias anteriores aos dois trabalhos de campo realizados nas datas: 07 de fevereiro de 2009 e 21 de outubro de 2009.

Para a obtenção dos dados limnológicos foram realizados trabalhos de campo nos dias 07 de fevereiro de 2009 e 21 de outubro de 2009, em um único ponto na foz do rio Ingaí, localizado na transição com o reservatório de Passo Real. Os dados da variável transparência da água (DS) foram obtidos nos dias de campo utilizando um disco de Secchi. A partir de análises das amostras de água foram determinadas as variáveis total de sólidos em suspensão (TSS) e clorofila $a(\mathrm{Chl} a)$. Os valores de TSS foram obtidos em laboratório com método de filtragem das amostras de água conforme apresentado em American Public Health Association (APHA) (2005). A Chl $a$ foi identificada conforme o método proposto por Mackinney (1941). Segundo esse método, a medida de absorbância da Chl $a$, medida em espectrofotômetro, ocorre nos comprimentos de onda de $663 \mathrm{~nm}$ e em $750 \mathrm{~nm}$.

Com base nas análises dos mapas de uso e cobertura da terra e dos dados limnológicos verificou-se as possíveis influências da precipitação pluviométrica sobre as características das variáveis limnológicas do rio Ingaí.

\section{RESULTADOS E DISCUSSÃO}

A utilização de imagens de satélite de períodos distintos do processo de uso e ocupação da bacia hidrográfica do rio Ingaí e dados de precipitação pluviométrica, possibilitaram obter informações da organização ocupacional da mesma, bem como analisar as possíveis influências na qualidade da água deste rio.

A obtenção dos dados pluviométricos anterior a coleta de campo é de fundamental importância para estudos referente a dados limnológicos, uma vez que interferem na sua propriedade.

Observa-se na Figura 2, que as ocorrências de chuva próxima da atividade de campo foram nos dias 3 e 4 de fevereiro de 2009, registrando 16,6 $\mathrm{mm}$ e 23,1 respectivamente, totalizando $39,7 \mathrm{~mm}$, ou seja, 3 dias antes da coleta de campo.

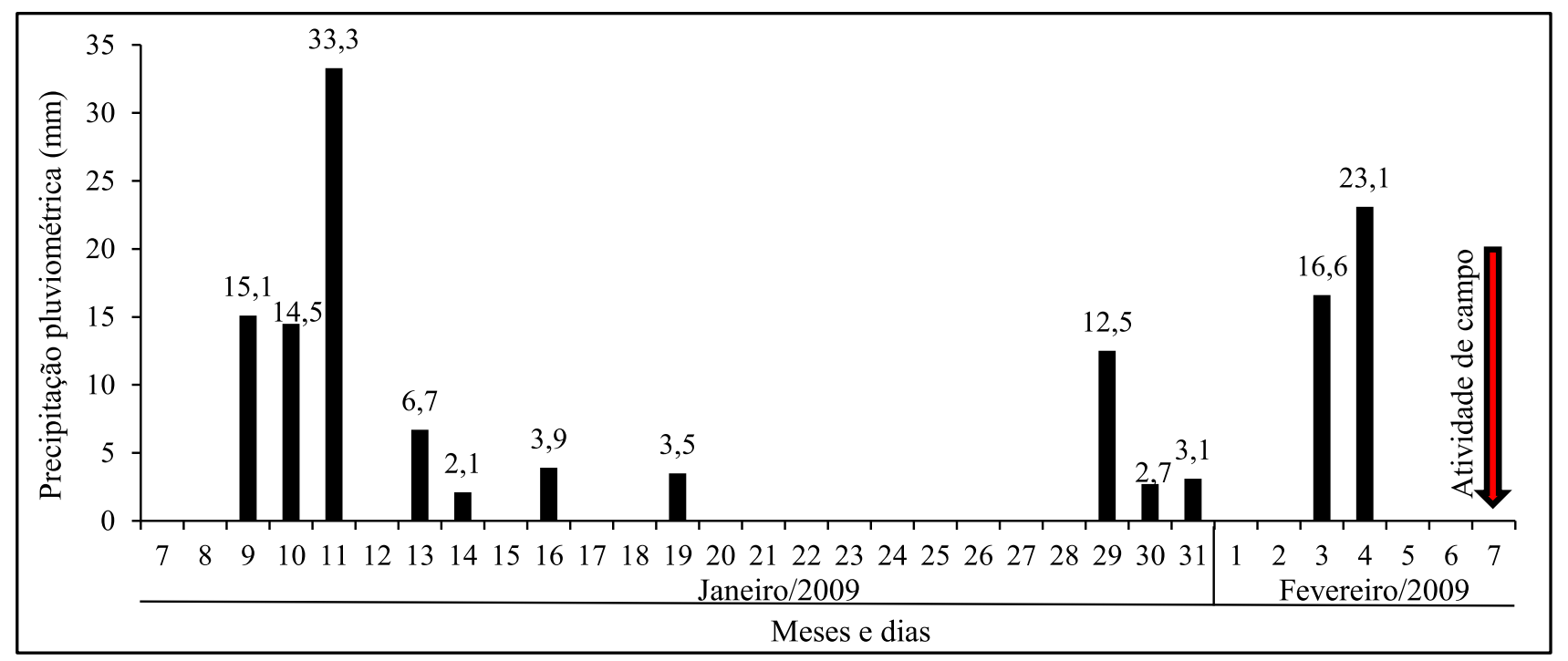

Figura 2: Dados de precipitação pluviométrica diária em 30 dias anteriores a coleta de campo realizada no dia 07 de fevereiro de 2009. Fonte: INMET (2015).

No levantamento de campo realizado no dia 21 de outubro de 2009 (Figura 3), observa-se que foi registrado $20,1 \mathrm{~mm}$ de chuva no dia 15 de outubro e $51,2 \mathrm{~mm}$ no dia 12 de outubro de 2009 , ou seja, $6^{\circ}$ e $9^{\circ}$ dias anteriores a atividade de campo, respectivamente.

\section{Uso e cobertura da terra}

De acordo com a classificação das imagens de satélite pode-se determinar os diferentes usos da terra na bacia hidrográfica. Observa-se a abrangência de extensas áreas das classes solo exposto e agricultura nos dois períodos analisados (Figura 4). Nota-se pivôs centrais de irrigação para o campo realizado em janeiro com desenvolvimento vegetativo e para o campo em outubro em fase de preparo do solo para plantio. 
A floresta desempenha um papel fundamental na redução dos poluentes nitrogênio e fósforo, além de possuir um papel importante de controle na regulação da qualidade da água (HUANG et al., 2013), uma vez que diminui o processo erosivo e da lixiviação do solo para os cursos d'água (DECHEN et al., 2015). Mesmo assim, observa-se que a classe floresta da bacia hidrográfica do rio Ingaí para ambos os períodos (Figura 4), restringese principalmente no entorno da rede de drenagem, devido a evolução do uso e ocupação da terra.

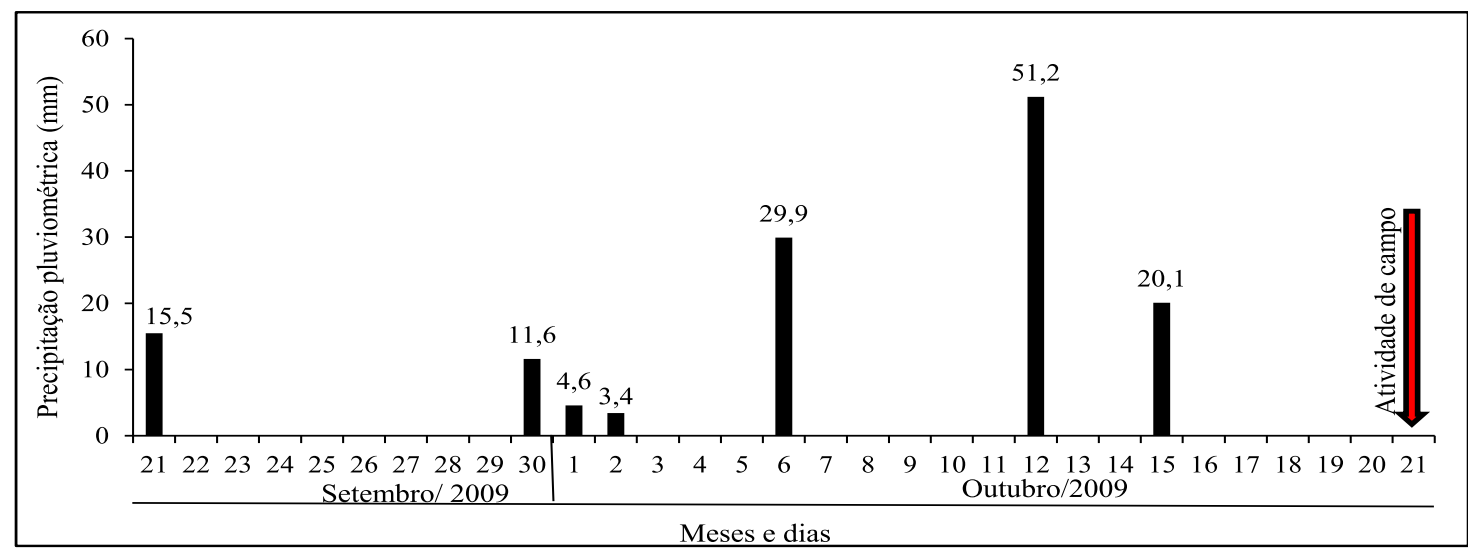

Figura 3: Dados de precipitação pluviométrica diária em 30 dias anteriores a coleta de campo realizada no dia 21 de outubro de 2009. Fonte: INMET (2015).

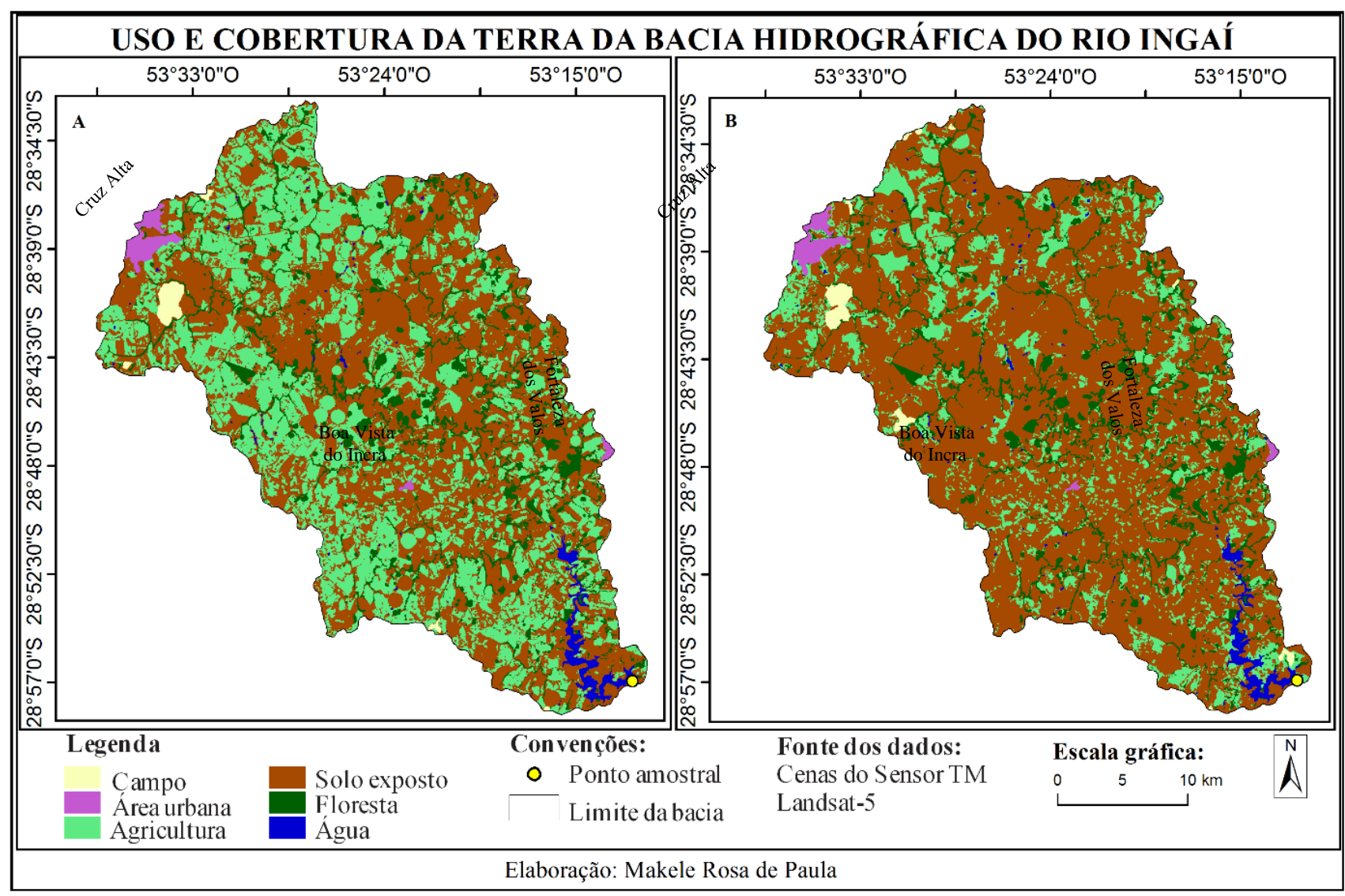

Figura 4: Mapas de uso e cobertura da terra da bacia hidrográfica do rio Ingaí: (A) em 21 de janeiro e (B) 20 de outubro de 2009.

Na Tabela 1 são apresentadas as áreas e porcentagem das classes temáticas para os dois períodos estudados. Quanto às alterações no uso e cobertura da terra na área de estudo, para os dois períodos analisados, o cálculo de áreas indicou maior área ocupada pelo solo exposto, seguido pela classe agricultura. Porém, cabe ressaltar que no mês de janeiro, $38 \%$ da bacia foi ocupada por agricultura, enquanto que no mês de outubro apenas 
17\% para esta mesma classe temática. Quanto a área de solo exposto, no mês de janeiro foi de 50\% da bacia, passando a representar $71 \%$ da área para o mês de outubro por ser um período de entressafra.

Tabela 1: Áreas das classes de uso e cobertura da terra da bacia hidrográfica do rio Ingaí - RS para as datas 21 de janeiro e 20 de outubro de 2009.

\begin{tabular}{c|c|c|c|c}
\hline \multirow{2}{*}{ Datas } & \multicolumn{2}{c|}{ 21 de janeiro de 2009 } & \multicolumn{2}{c}{ 20 de outubro de 2009 } \\
\cline { 2 - 5 } & Área $\left(\mathbf{K m}^{\mathbf{2}}\right)$ & Porcentagem $(\%)$ & Área $\left(\mathbf{K m}^{2}\right)$ & Porcentagem (\%) \\
\hline Água & 13,33 & 1 & & 1 \\
\hline Floresta & 96,30 & 9 & 96,56 & 9 \\
\hline Solo exposto & 518,11 & 50 & 739,01 & 71 \\
\hline Agricultura & 401,76 & 38 & 177,90 & 17 \\
\hline Área urbana & 9,83 & 1 & 9,83 & 1 \\
\hline Campo & 6,52 & 1 & 8,61 & 100 \\
\hline Total & 1045,8 & 100 & 1045,8 & 1 \\
\hline
\end{tabular}

Fonte: Cena 223/80 do sensor TM/Landsat-5.

A classe floresta ocupa apenas $9 \%$ da bacia hidrográfica do rio Ingaí para ambos os períodos. Esta baixa porcentagem da classe floresta indica uma substituição de vegetação nativa para atividades agrícolas. De acordo com Kramer e Pereira Filho (2011), o relevo colinoso suave da bacia hidrográfica do rio Ingaí propicia o desenvolvimento, em larga escala, da agricultura.

A classe campo para as datas analisadas representaram $1 \%$ da área total da bacia hidrográfica. Segundo Wachholz (2011), algumas áreas de campo na bacia hidrográfica do Alto Jacuí são utilizadas durante o inverno para pecuária e no verão são substituídas por algum tipo de cultura anual, o que explica a baixa abrangência de áreas ocupadas por campo na área de estudo.

Como esperado, as classes água, floresta e área urbana, apresentaram o mesmo percentual nos dois períodos estudados, correspondendo a 1\%, 9\% e 1\%, respectivamente (Tabela 1). A classe água representa os açudes, rios e o braço do reservatório Passo Real.

Na conversão da cobertura de vegetação para área urbana ocorre erosões dos solos e, como consequência, aumenta a quantidade de fósforo no escoamento (HUANG et al., 2013), atingindo assim os corpos d'águas. Nesse sentido, cabe destacar as áreas urbanas presentes na bacia, as quais compreendem parte das cidades de Cruz Alta (a noroeste da bacia) e Fortaleza dos Valos (a leste), e a cidade de Boa Vista do Incra (próximo a região central da bacia).

\section{Variáveis limnológicas}

Considerando os dados limnológicos obtidos in situ, os dados de precipitação pluviométrica e as mudanças associadas às diferentes práticas do uso e cobertura da terra da bacia em estudo, realizaram-se as análises e integração dos dados.

A condutividade elétrica obtida no campo do dia $07 / 02 / 2009$ foi de $58,9 \mu \mathrm{S} / \mathrm{cm}$ e no campo do dia $21 / 10 / 2009$ de 27,5 $\mu \mathrm{S} / \mathrm{cm}$ (Tabela 2). Estes valores de condutividade elétrica comparados aos estudos realizados por Gonçalves et al. (2011), na bacia hidrográfica do rio Santo Anastácio, são considerados baixos, pois os autores encontraram valores de condutividade elétrica de até $852 \mu \mathrm{S} / \mathrm{cm}$, concluindo que, esses valores podem ter sido influenciados, além da geologia e pedologia, pelo uso da terra, principalmente devido a agricultura. Valores de condutividade elétrica encontrados por Ferreira et al. (2012) em três sub-bacias hidrográficas na região central do Rio Grande do Sul, áreas próximas a bacia do rio Ingaí, variaram de 56,3 a $68,7 \mu \mathrm{S} / \mathrm{cm}$ para a sub-bacia do rio Ibicuí-Mirim, isso por se encontrar totalmente fora da área urbana. Já para o rio Vacacaí-Mirim e o arroio Cadena variaram de 207 a $397 \mu \mathrm{S} / \mathrm{cm}$ e 455 a $563 \mu \mathrm{S} / \mathrm{cm}$, respectivamente, isso devido à proximidade com área urbana. 
No campo de fevereiro, período de desenvolvimento vegetativo (agricultura), o valor de condutividade elétrica de 58,9 $\mu \mathrm{S} / \mathrm{cm}$ coincidiu quando a temperatura foi mais alta $\left(27,2^{\circ} \mathrm{C}\right)$. CETESB (2009), Oliveira e Cunha (2014) afirmam que, a condutividade elétrica depende diretamente da temperatura. Segundo Mosca (2003), essa variável limnológica pode ser alterada em decorrência da entrada de fertilizantes e defensivos agrícolas que acabam aumentando as concentrações iônicas nos corpos d'água. Tong e Chen (2002) afirmaram que o uso agrícola foi fortemente relacionado à condutividade elétrica.

Tabela 2: Dados das variáveis limnológicas no ponto de coleta localizado na foz do rio Ingaí.

\begin{tabular}{c|c|c}
\hline Variáveis limnológicas & Campo dia 07/02/2009 & Campo dia 21/10/2009 \\
\hline Cor & Verde marrom & Verde \\
\hline Disco de Sechhi $(\mathrm{m})$ & 1,45 & 0,38 \\
\hline Temperatura $\left({ }^{\circ} \mathrm{C}\right)$ & 27,2 & 23,9 \\
\hline $\mathrm{pH}$ & 7,0 & 7,35 \\
\hline $\mathrm{Chl} a(\mu \mathrm{g} / \mathrm{l})$ & 9,26 & 439,52 \\
\hline $\mathrm{TSS}(\mathrm{mg} / \mathrm{l})$ & 3,0 & 42,00 \\
\hline $\mathrm{CE}(\mu \mathrm{S} / \mathrm{cm})$ & 58,9 & 27,5 \\
\hline
\end{tabular}

Fonte: Atividade de campo.

O total de sólidos em suspensão para o campo realizado no dia 07/02/2009 foi inferior ao campo do dia 21/10/2009 (Tabela 2), o que provavelmente se deve a menor ocorrência das áreas de solo exposto nesse período, comparado ao segundo campo, embora tenham ocorrido precipitações pluviométricas 3 dias antes da coleta desse dado limnológico. De acordo com Kramer (2009), em fevereiro, nesta mesma área, a terra encontra-se coberta, principalmente, pelo cultivo da soja e do milho, evitando a exposição e lixiviação do solo.

A concentração do total de sólidos em suspensão para o campo de outubro foi de $42 \mathrm{mg} / \mathrm{l}$ (Tabela 2) coincidindo com a maior área de solo exposto ( $71 \%$ da bacia) (Tabela 1), ocorrência de precipitação pluviométrica 6 dias anteriores a coleta de campo $(20,1 \mathrm{~mm})$ (Figura 3) e baixa transparência da água $(0,38 \mathrm{~m})$ (Tabela 2). Uma vez que os solos desprovidos de cobertura vegetal proporcionam o processo de erosão o que tende a uma elevada quantidade de sólidos carreados para os corpos d'água (CURRAN e NOVO, 1988; LATRUBESSE et al., 2005; TYLER et al., 2006; KRAMER e PEREIRA FILHO 2011; LATRUBESSE et al., 2012).

Sabe-se que as concentrações de sólidos em suspensão e clorofila $a$ são inversamente proporcional à transparência da água, ou seja, a transparência da água diminui à medida que a concentração de sólidos em suspensão e clorofila $a$ aumenta. Na Tabela 2, observa-se que as menores concentrações de sólidos em suspensão $(3,0 \mathrm{mg} / \mathrm{l})$ e clorofila $a(9,26 \mu \mathrm{g} / \mathrm{l})$ ocorreram no campo de fevereiro, o qual apresentou uma maior transparência da água $(1,45 \mathrm{~m})$ comparado com o campo de outubro que obteve valores de TSS de $42 \mathrm{mg} / \mathrm{l}$ e clorofila $a$ de $439,52 \mu \mathrm{g} / 1$ obtendo menor transparência $(0,38 \mathrm{~m})$.

A alta concentração de clorofila $a(439,52 \mu \mathrm{g} / \mathrm{l})$, no mês de outubro, deve-se ao aumento de nutrientes na água. Os sedimentos servem como transportador e armazenador de pesticidas, fósforo absorvido, nitrogênio e compostos orgânicos (LODHI et al., 1997), o que afeta a qualidade da água. Segundo CETESB (2014), o enriquecimento de nutrientes na água, principalmente por nitrogênio e fósforo, causa a eutrofização que é um indicador do crescimento de algas e cianobactérias.

Estudos realizados por Wachholz (2011), durante uma série temporal do reservatório Passo Real em 2009, permitiram verificar que as médias de clorofila $a$ para os meses de fevereiro a julho (meses menos chuvosos) foram baixas, caracterizando o ambiente do reservatório como mesotrófico e para os meses de agosto a março de 2010 (meses chuvosos) as concentrações de clorofila $a$ foram altas, caracterizando o ambiente do reservatório de eutrófico a hipereutrófico.

Desta maneira, os dados de concentração de clorofila $a$ permitiram classificar o campo realizado no mês de fevereiro como mesotrófico $(3,24<\operatorname{chl} a \leq 11,03)$ e para o campo realizado em outubro como hipereutrófico $(69,05<\operatorname{chl} a)$, de acordo com a classificação de estado trófico proposta por Carlson (1977) modificado por 
Lamparelli (2004). Estudos realizados por Pereira Filho et al. (2011) no reservatório Passo Real, ressaltam que as águas do rio Ingaí ao atingir o reservatório Passo Real, podem apresentar maior período de residência, podendo ser considerada a zona de transição que proporciona condições favoráveis a altos valores de clorofila.

O valor do pH no campo realizado em 07/02/2009 foi 7 (neutro) e no campo de 21/10/2009 foi de 7,35 (alcalina) (Tabela 2), o que demonstra pouca variação para os dois períodos analisados. De acordo com a resolução CONAMA 357/2005, estes resultados são considerados satisfatórios, pois estão dentro dos limites de padrões de qualidade das águas, que é de 6 a 9 (BRASIL, 2005).

A variação da temperatura da água deve-se, principalmente, ao período do ano, visto que a primeira atividade a campo foi realizada no período de verão (07/02/2009), onde ocorrem as maiores temperaturas, obtendo assim temperatura de $27,2^{\circ} \mathrm{C}$, enquanto que no campo de $21 / 10 / 2009$ registrou $23,9^{\circ} \mathrm{C}$, período de primavera (Tabela 2). A ocorrência de maior temperatura para o campo realizado em fevereiro coincidiu com a maior transparência da água $(1,45 \mathrm{~m})$. Segundo Sartor (2008), a temperatura da água é diretamente proporcional a transparência da água e inversamente proporcional a concentração de TSS, isto é, quanto maior a temperatura maior a transparência da água e, portanto, menor a concentração de TSS.

A cor da água fornece algumas informações dos constituintes opticamente ativos presentes na mesma. Assim, realizou-se uma análise visual da água do rio Ingaí, e observou-se tons em verde e marrom para o campo realizado em fevereiro, o qual pode estar relacionado a presença de sólidos em suspensão e clorofila, e tonalidade de verde para o campo em outubro, devido à alta concentração de clorofila $a$ na água.

\section{CONCLUSÃO}

A avaliação integrada dos sistemas aquático e terrestre, permitiu concluir que a alteração das propriedades da água do rio Ingaí possui forte relação com as alterações no uso e cobertura da terra da bacia hidrográfica, provenientes principalmente de fontes difusas, devido à extensa área destinada a agricultura, áreas de solo exposto, aliados a ocorrência de precipitação pluviométrica.

Os índices pluviométricos em relação ao uso e cobertura da terra influenciaram no resultado das variáveis limnológicas em maior ou menor aporte de sedimentos e nutrientes carreado para o leito do rio. As diferenças mais expressivas ocorreram nas concentrações do total de sólidos em suspensão e de clorofila $a$.

No mês de outubro, período em que ocorreu maior área de solo exposto, associado a ocorrência de precipitação pluviométrica, verificou-se que a influência do ambiente terrestre sobre o ambiente aquático foi maior devido a facilidade de escoamento contribuindo para uma elevada carga de sedimentos e nutrientes para o corpo d'água.

Com base na concentração de clorofila $a$ como indicadora do estado trófico encontrou-se no ponto de coleta da foz do rio Ingaí ambiente mesotrófico para o mês de fevereiro e hipereutrófico para o mês de outubro. Os resultados desta pesquisa fornecem subsídios aos órgãos gestores e a sociedade para a implementação de medidas de planejamento estratégico de gestão dos recursos hídricos na bacia hidrográfica do rio Ingaí.

\section{AGRADECIMENTOS}

Os autores agradecem ao Conselho Nacional de Desenvolvimento Científico e Tecnológico (CNPq), pelo auxílio financeiro para realização desta pesquisa.

\section{REFERÊNCIAS}

APHA - American Public Health Association. Standard Methods for the Examination of Water and Waster water. 21 ed. Sprimgfield: Byrd Prepress, 2005.

BRASIL. Resolução CONAMA nº 357, de março de 2005. Conselho nacional do meio ambiente - CONAMA. Dispõe sobre a classificação dos corpos de água e diretrizes ambientais para o seu enquadramento, bem como estabelece as condições e padrões de lançamento de efluentes, e dá outras providências. Mar. 2005. Disponível em: <http://www.mma.gov.br/port/conama/res/res05/res35705.pdf>. Acesso em: 21 de out. 2015.

CARLSON, R. E. A trophic state index for lakes. Limmolology Oceanography, v. 22, p. 361-80, 1977. 
CETESB - Companhia Ambiental do Estado de São Paulo. Qualidade das águas interiores no estado de São Paulo: significado ambiental e sanitário das variáveis de qualidade das águas e dos sedimentos e metodologias analíticas e de amostragem. São Paulo: CETESB, 2009. 44 p. (série relatórios). Disponível em: <http://cetesb.sp.gov.br/aguas-interiores/wp-content/uploads/sites/32/2013/11/variaveis.pdf> Acesso em: 21 de out. 2015.

CETESB (Companhia de Tecnologia de Saneamento Ambiental). Determinação de Clorofila a e Feofitina a: método espectrofotométrico. São Paulo: CETESB, p. 14, 2014.

CURRAN, P. J.; NOVO, E. M. M. The relationship between suspended sediment concentration and remotely sensed spectral radiance: a review. Journal of Coastal Research, v. 4, n. 3, p. 351-368, 1988.

DECHEN, S. C. F.; TELLES, T. S.; GUIMARAES, M. F.; MARIA, I. C. Perdas e custos associados à erosão hídrica em função de taxas de cobertura do solo. Bragantia, São Paulo, v. 74, n. 2, p. 224-233, 2015.

ESRI - ENVIRONMENTAL SYSTEMS RESEARCH INSTITUTE. ArcGIS for the desktop, versão 10.1, USA, 2013.

FERREIRA, A. B; PEREIRA FILHO, W.; ROSA, R. Análise comparativa de variáveis limnológicas em três subbacias hidrográficas na região central do Rio Grande do Sul-Brasil. Caminhos de Geografia, v.13, n. 41, p. 15$28,2012$.

GONÇALVES, F.; ROCHA, P. C.; FERREIRA, C. C. Uso e ocupação da terra e suas influências em parâmetros químicos e físicos da água da bacia hidrográfica do rio Santo Anastácio, Oeste Paulista. In: SIMPÓSIO BRASILEIRO DE SENSORIAMENTO REMOTO, 15., 2011, Curitiba/PR. Anais... Curitiba/PR: Instituto Nacional de Pesquisas Espaciais, 2011, p. 1248 - 1255.

HASENACK, H.; WEBER, E. (org.). Base cartográfica vetorial continua do Rio Grande do Sul - escala 1:50.000. Porto Alegre: UFRGS Centro de Ecologia, 2010. 1 DVD-ROM.

HUANG, J.; ZHAN, J.; YAN, H.; WU, F.; DENG, X. Evaluation of the Impacts of Land Use on Water Quality: A Case Study in The Chaohu Lake Basin. The Scientific World Journal. p. 1-7, 2013.

IBGE. Mapa de Vegetação 2004. IBGE: Rio de Janeiro, 2004. Disponível em <ftp://geoftp.ibge.gov.br/mapas_tematicos/mapas_murais/vegetacao.pdf>. Acesso em 12 jun. 2015.

IBGE. Mapa de Solos do Brasil. IBGE: Rio de Janeiro, 2001. Disponível em: <ftp://geoftp.ibge.gov.br/mapas_tematicos/mapas_murais/solos.pdf>. Acesso em 12 jun. 2015.

INMET INSTITUTO NACIONAL DE METEOROLOGIA. 2015. Disponível em: < http://www.inmet.gov.br/portal/> Acesso em: 25 de jun. 2015.

INSTITUTO NACIONAL DE PESQUISAS ESPACIAIS (INPE) - Manuais: tutorial de geoprocessamento SPRING. 2008.

KRAMER, G. Avaliação espaço-temporal das avaliações entre ecossistemas terrestre e aquático: estudo de caso da bacia da UHE Passo Real da região sul do Brasil. 2009. 90 p. Dissertação (Mestrado em Geografia) - Universidade Federal de Santa Maria, Santa Maria, RS, 2009.

KRAMER, G.; PEREIRA FILHO, W. Avaliação espaço-temporal das relações entre ecossistemas terrestre e aquático: estudo de caso da bacia da UHE Passo Real da região sul do Brasil. In: SIMPÓSIO BRASILEIRO DE SENSORIAMENTO REMOTO, 15., 2011, Curitiba/PR. Anais... Curitiba/PR: Instituto Nacional de Pesquisas Espaciais, 2011, p. 4185 - 4193.

LAMPARELLI , M. C. Grau de trofia em corpos d'água do estado de São Paulo: avaliação dos métodos de monitoramento. São Paulo: USP/ Departamento de Ecologia. 2004. 237 p. Tese (Doutorado em Ecossistemas Terrestres e Aquáticos) - Universidade de São Paulo, São Paulo, SP, 2004.

LATRUBESSE, E. M.; STEVAUX, J. C.; SINHA, R. Tropical rivers. Geomorphology, v. 70, 2005, p. 187-206.

LATRUBESSE, E. Amazon lakes. In: L. Bengtsson; R. Herschy; R. Fairbridge (Orgs.), Lakes and reservoirs. Springer Verlag, p. 13-26, 2012.

LODHI, M. A.; RUNDQUIST, D. C.; LUOHENG, H.; KUZILA, M. S. The potential for remote sensing of loess soils suspended in surface waters. Journal of the American Water Resources Association, v. 33, n.1, p.111117, 1997. 
MACKINNEY, G. Absorption of light by chlorophyll solutions. The Journal of Biological Chemistry. v. 140, p. $315-322,1941$.

MENDONÇA, F., DANNI-OLIVEIRA, I. M. Climatologia: noções básicas e climas do Brasil. São Paulo: Oficina de Textos, 2007. 206 p.

MISERENDINO, M. L.; CASAUX, R.; ARCHANGELSKY, M.; PRINZIO, C. Y. di, BRAND, C.; KUTSCHKER, A. M. Assessing land-use effects on water quality, in-stream habitat, riparian ecosystems and biodiversity in Patagonian northwest streams. Science of the Total Environment. p. 612-624, 2011.

MOSCA, A. A. O. Caracterização hidrológica de duas microbacias visando a identificação de indicadores hidrológicos para o monitoramento ambiental do manejo de florestas plantadas. 2003, 120 p. Dissertação (Mestrado em Recursos Florestais) - Escola Superior de Agricultura Luiz de Queiroz, Piracicaba, SP, 2003.

OLIVEIRA, B. S. S. de, CUNHA, A. C. da. Correlação entre qualidade da água e variabilidade da precipitação no sul do Estado do Amapá. Revista Ambiente \& Água, v. 9, n. 2, p. 261-275, 2014.

PEREIRA FILHO, W.; BARBIERI, D. W.; WACHHOLZ, F.; CORAZZA, R.; TRENTIN, A. B.; DOMINGUES, A. L. Relação entre clorofila $a$ com perfil espectral e imagem de satélite no reservatório Passo Real - RS. In: SIMPÓSIO BRASILEIRO DE SENSORIAMENTO REMOTO, 15., 2011, Curitiba/PR, Anais... Curitiba/PR: Instituto Nacional de Pesquisas Espaciais, 2011, p. 5433 - 5440.

REIS, J. T. Influência do uso e ocupação da terra no ecossistema aquático da sub-bacia hidrográfica do Arroio Cadena, em Santa Maria - RS. 2006. 110 p. Dissertação (Mestrado em Geomática) - Universidade Federal de Santa Maria, Santa Maria, RS, 2006.

ROSA, R. Introdução ao sensoriamento remoto. 7. ed., Uberlândia: Ed. EDUFU, 2009. 264 p.

ROSS, J. L. S. Ecogeografia do Brasil: subsídios para planejamento ambiental. São Paulo: Oficina de Textos, 2006. 208 p.

SARTOR, S. C. de B. Avaliação temporal de variáveis limnológicas do reservatório Rodolfo Costa e Silva RS, e o uso da terra na área de captação. 2008. 94 p. Dissertação (Mestrado em Geografia) - Universidade Federal de Santa Maria, Santa Maria, RS, 2008.

TYLER, A. N.; SVAB, E.; PRESTON, T.; PRESING, M.; KOVACS,W. A. Remote sensing of the water quality of shallow lakes: A mixture modelling approach to quantifying phytoplankton in water characterized by highsuspended sediment. International Journal of Remote Sensing, v. 27, p. 1521-1537, 2006.

TONG, S. T. Y.; CHEN, W. Modeling the relationship between land use and surface water quality. Journal of Environmental Management, n. 66, p. 377-393, 2002.

TUNDISI, J. G. \& TUNDUSI, T. M. Limnologia. São Paulo: Oficina de textos, 2008, 632 p.

WACHHOLZ, F. Influência das bacias hidrográficas e características espaço-temporal de variáveis limnológicas em reservatórios no Rio Grande do Sul. 2011. 191 p. Tese (Doutorado em Geografia) Universidade Estadual Paulista, Rio Claro, SP, 2011. 